\title{
Leading By Example: How Medical Journals Can Improve Representation in Academic Medicine
}

\author{
Samir S Shah, MD, MSCE ${ }^{1 *}$; Erin E Shaughnessy, MD, MSHCM²; Nancy D Spector, MD³
}

'Divisions of Hospital Medicine and Infectious Diseases, Cincinnati Children's Hospital Medical Center, University of Cincinnati College of Medicine, Cincinnati, Ohio; 'Division of Hospital Medicine, Phoenix Children's Hospital, University of Arizona School of Medicine, Phoenix, Arizona; ${ }^{3}$ Office of Faculty Development and the Executive Leadership in Academic Medicine Program, Drexel University College of Medicine, Philadelphia, Pennsylvania.

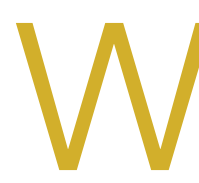

omen and racial and ethnic minorities remain underrepresented in senior faculty roles and academic leadership positions. ${ }^{1}$ Participation in peer review and publication in medical journals are important components of academic advancement that are emphasized in the promotion process. These efforts offer recognition of expertise and increase visibility in the scientific community, which may enhance opportunities for networking and collaboration, and provide other opportunities for career advancement. In addition, abundant evidence shows that organizations benefit from diverse teams, with better quality decisions and increased productivity resulting from diverse ideas and perspectives. ${ }^{2}$

Numerous studies have highlighted the prevalence and persistence of disparities in peer review and authorship.,4 Much of this work has focused on gender though gaps in these measures likely exist for racial and ethnic minorities. Yet, there are few examples of journals implementing strategies to address disparities and track results of such efforts. ${ }^{5}$ While institutional barriers to advancement must be addressed, we believe that medical journals have an obligation to address unequal opportunities.

At the Journal of Hospital Medicine, we are committed to leading by example and developing approaches to create equity in all facets of journal leadership and authorship. ${ }^{6}$ The first step towards progress is to assess the current representation of women and racial and ethnic minorities in our journal community, including first and senior authors, invited expert contributors, reviewers, and editorial team members. Like most journals, we have not collected demographic information from authors or reviewers. But now, as part of the journal's commitment to this cause, we request that everyone in the jour-

*Corresponding Author: Dr. Samir S. Shah, E-mail: Samir.Shah@cchmc.org; Telephone: 513-636-6222; Twitter: @SamirShahMD

Published online first June 18, 2019.

Received: May 13, 2019; Accepted: May 13, 2019

๑ 2019 Society of Hospital Medicine DOI 10.12788/jhm.3247 nal community (author, reviewer, editor) update their journal account (accessible at https://mc.manuscriptcentral.com/jhm) with demographic data, including gender, race, and ethnicity.

Inclusion of these data is voluntary. While each individual will be able to access and edit their personal demographic data, the individual data will remain private and unviewable to others. As such, it will not be available for nor will it be used in the manuscript review or decision process but rather for assessing our own inclusiveness. We will review these data in aggregate to broadly inform outreach efforts to promote diversity and inclusion in our author, invited expert contributor, reviewer, and journal leadership pools. We will report on the progress of these efforts in upcoming years.

We are committed to equity in providing opportunities for academic advancement across the journal community. Diversity and inclusion are important in raising the quality of the work that we publish. Different perspectives strengthen our journal and will help us continue to advance the field of Hospital Medicine.

Disclosures: The authors have nothing to disclose.

\section{References}

1. American Association of Medical Colleges. U.S. Medical School Faculty, 2018. https://www.aamc.org/data/facultyroster/reports/494946/usmsf18. html. Accessed May 6, 2019

2. Turban S, Wu D, Zhang L. "When Gender Diversity Makes Firms More Productive." Harvard Business Review Feb 2019. https://hbr.org/2019/02/research-when-gender-diversity-makes-firms-more-productive. Accessed May 6, 2019.

3. Silver JK, Poorman JA, Reilly JM, Spector ND, Goldstein R, Zafonte RD. Assessment of women physicians among authors of perspective-type articles published in high-impact pediatric journals. JAMA Netw Open. 2018;1(3):e180802. doi: 10.1001/jamanetworkopen.2018.0802.

4. Jagsi R, Guancial EA, Worobey CC, Henault LE, Chang Y, Starr R, Tarbell NJ, Hylek EM. The "gender gap" in authorship of academic medical literature- a 35-year perspective. N Engl J Med. 2006;355(3):281-287. doi: 10.1056/NEJMsa053910.

5. Nature's under-representation of women. Nature. 2018;558:344. doi: 10.1038/d41586-018-05465-7.

6. Shah SS. The Journal of Hospital Medicine in 2019 and beyond. $J$ Hosp Med. 2019;14(1):7. doi: 10.12788/jhm.3143. 